\title{
La Universidad ante las tendencias socioeconómicas actuales y los Objetivos de Desarrollo Sostenible
}

\author{
Germán Anzola Montero' \\ ${ }^{1}$ Rector. Universidad de Ciencias Aplicadas y Ambientales U.D.C.A, (D) https://orcid.org/0000-0001-6075-2595
}

Como citar: Anzola Montero, G. 2020. La Universidad ante las tendencias socioeconómicas actuales y los Objetivos de Desarrollo Sostenible. Rev. U.D.C.A Act. \& Div. Cient. 23(2):e1662. http://doi.org/10.31910/rudca.v23.n2.2020.1662

Artículo de acceso abierto publicado por Revista U.D.C.A Actualidad \& Divulgación Científica, bajo una licencia Creative Commons CC BY-NC 4.0

Publicación oficial de la Universidad de Ciencias Aplicadas y Ambientales U.D.C.A, Institución de Educación Superior Acreditada de Alta Calidad por el Ministerio de Educación Nacional.

La reflexión para este Editorial, dirigida a la Revista U.D.C.A Actualidad \& Divulgación Científica, fue expuesta en el reciente Encuentro Virtual Educa Connect, del 21 al 23 de julio de 2020, donde líderes, representantes y docentes de la educación mundial, debatieron sobre su futuro, a través de la innovación digital y otros asuntos relevantes, dada la contingencia de pandemia de la Covid-19.

Tanto Naciones Unidas como otros expertos en desarrollo sostenible vaticinan, con seguridad, que la pandemia de coronavirus va a tener un fuerte impacto en la Agenda 2030, que puede ser positivo, como es el caso del cambio climático o una impresión negativa, especialmente, en lo que se refiere al detrimento de la salud comunitaria y al incremento de las desigualdades, debido a la desaceleración económica mundial.

El análisis que se adelantó a los Objetivos de Desarrollo Sostenible - ODS, corresponde al informe "Responsabilidad compartida, solidaridad global: una respuesta a los impactos socioeconómicos de la COVID-19" de Naciones Unidas y que fue compilado por el Centro de Desarrollo Sostenible para América Latina (CODS). En el documento, se destacan, principalmente, 13 de los 17 Objetivos, que señala, entre otras preocupaciones: ingresos bajos para las familias; escases de alimento; el sistema de salud y el bienestar en las personas, como efecto devastador; incremento del desempleo; personas sin acceso a la educación remota; poblaciones con pocas o nulas instalaciones sanitarias adecuadas para evitar la propagación del virus; suspensión de actividades laborales y otras (Figura 1).
En este nuevo lapso, que comenzó siendo la Década para la Acción en los Objetivos de Desarrollo Sostenible, nos encontramos ante una crisis económica y sanitaria, que marcará un punto de inflexión para la Agenda 2030. Estamos en el momento, en que nuestros esfuerzos deben aportar al repunte hacia el mundo que queremos o a un punto de no retorno. Es un campanazo para todas las Naciones a actuar, para detener la propagación del virus y poner fin a la pandemia y establecer soluciones a las dimensiones sociales y económicas, derivadas de esta crisis.

A pesar de todo, esta vicisitud ha traído enseñanzas positivas, dándole prioridad al trabajo en los ODS, como es el caso, del número 3, que corresponde a salud. Las Naciones Unidas refieren a la "necesidad de reforzar la resiliencia de los sistemas de salud para frenar la expansión del virus", prestar ayuda y colaboración, para aquellos países más afectados y que no cuentan con suficientes equipos médicos y elementos de protección.

También, desde los ODS, se analiza la crisis económica que deberán afrontan las familias y las empresas. No se oculta el hecho, que entre 5 y 25 millones de personas perderán su puesto de trabajo, según estimaciones de la Organización Internacional del Trabajo, OIT (2020), afectando los ingresos laborales; ni qué decir, de las pequeñas y medianas empresas, que ya se acercan al umbral de la pobreza.

Es imperativo no olvidar la necesidad de trabajar en otros Objetivos, vitales para la sostenibilidad del mundo: la Educación de calidad 


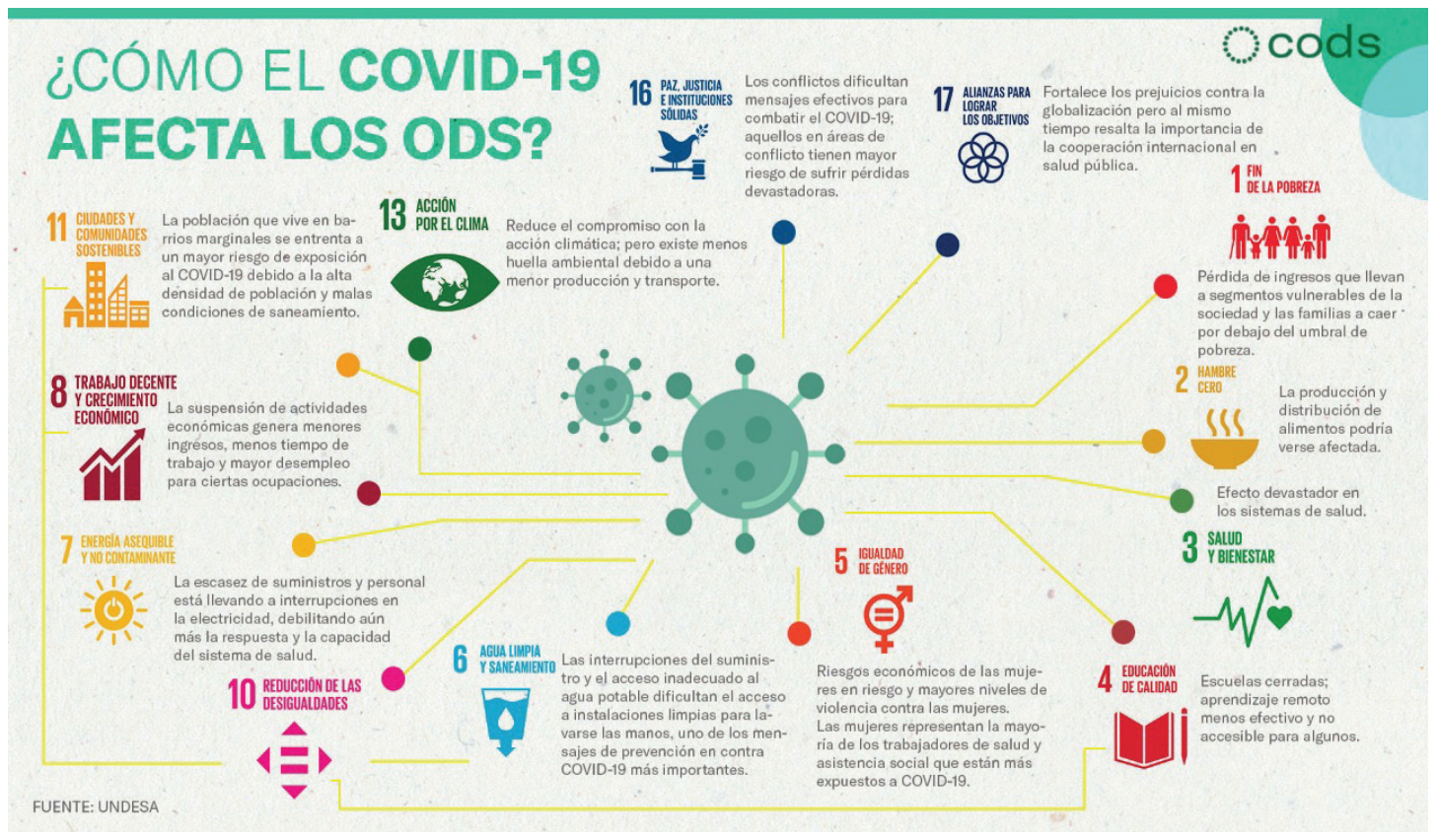

Figura 1. Puntos clave del informe de las Naciones Unidas (Imagen tomada de: https://unsdg.un.org/sites/default/files/2020-03/SGReport-Socio-Economic-Impact-of-Covid19.pdf).

(ODS-4), el cual, se ha tenido que replantear por completo ante la intempestiva llegada de la pandemia. El clamor es para que la comunidad internacional apoye a los gobiernos más vulnerables a buscar soluciones para que el aprendizaje continúe; favorecer a los padres y profesores para que se puedan adaptar a las nuevas modalidades de enseñanza; ofrecer posibilidades de acceso a la educación remota y, así, evitar que la brecha de desigualdad, en el acceso a la educación, se ahonde más.

Antes de la llegada de la pandemia a América Latina y el Caribe, el ODS 4 era el octavo en avance y reporte por parte de los países de la región. Aunque aún no se ha medido porcentualmente, la llegada del coronavirus, cambió por completo este panorama.

Hoy, este Objetivo se replantea, según las Naciones Unidas: "Educación a distancia mediante: acceso a préstamos o transferencias de equipos para estudiantes u hogares; suministro de conexión a internet y asociaciones público-privadas para hacer plataformas y herramientas para el aprendizaje a distancia disponibles de forma gratuita; esfuerzos públicos y privados para garantizar y ampliar la capacidad de las redes, es decir, los gobiernos y los operadores deben tener análisis de demanda de red y planes de Contingencia; recursos de aprendizaje digital para maestros y padres; dar a conocer los esfuerzos de los países para mantener la provisión de educación inclusiva en diferentes contextos; si las escuelas, en nuestro caso, Universidad, están abiertas, asegúrese de que las medidas de distanciamiento social, higiene y seguridad alimentaria y calidad siguen los estándares..."
Tal y como lo señala el Instituto Internacional de la UNESCO para la Educación Superior en América Latina y el Caribe, UNESCOIESALC, la pandemia del COVID-19 añadió un grado más de complejidad a la educación superior en la región, que viene de enfrentar retos no resueltos. Para ser francos, debemos reconocer que no estábamos preparados para una disrupción, a semejante escala. Casi, de la noche a la mañana, los colegios y las universidades de todo el mundo, cerraron sus puertas, afectando a 1.570 millones de estudiantes, en 191 países "los estudiantes se han visto forzados a entrar en una dinámica no planificada de clases a distancia, así como la continuidad de sus aprendizajes y la movilidad internacional" (IESALC, 2020) (Figura 2).

A partir de ese hecho, las Universidades tuvieron que ajustar su oferta, tradicionalmente presencial, a una enseñanza en línea o remota, que permitiera dar continuidad a las clases a distancia, priorizando el uso de las TIC, que facilitaron el proceso; sin embargo, en el análisis a esta situación de la educación, según IESALC, los resultados no son del todo satisfactorios, dado que un $25 \%$ de los estudiantes e instituciones no tuvieron esa capacidad real, en términos de tecnologías y plataformas, requeridas para la educación remota. Y es así, pues la mayoría de Instituciones de Educación Superior afrontaron esta nueva modalidad, de manera súbita e imprevisible. La urgente tarea, ahora, es planificar y desarrollar una educación virtual, más allá del 2021, con mayor infraestructura pedagógica y de recursos.

Esta situación, también representó inmensos desafíos para las redes y las asociaciones universitarias, que trabajaban por una 


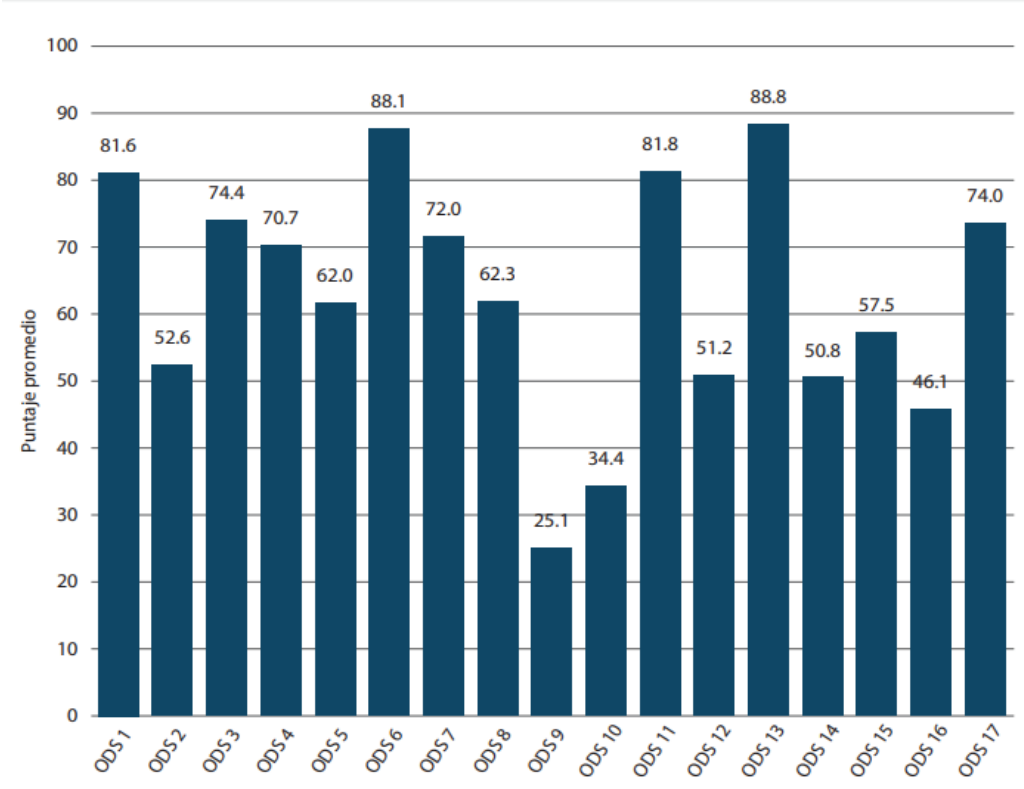

Antes de la pandemia en la región de América Latina y el Caribe, el índice desagregado por ODS, pone al ODS 4 en el puesto No. 8, con un reporte del 70,7

Figura 2. Resultado Índices ODS para América Latina y el Caribe por Objetivo (Imagen tomada de: CODS, 2020)

internacionalización regional, en términos de normalidad. A partir de la pandemia, se replanteó, de manera directa, la forma de "internacionalizar la educación superior", ya que se basaba, mayoritariamente, en la movilidad internacional.

En un mundo con fronteras aéreas y terrestres cerradas, la cooperación tradicional tuvo que pensarse con otros fines, en especial, en uno que, tímidamente, había sido propiciado: la virtualidad. A pesar de estos reveses, la crisis actual ha despertado nuevas oportunidades para la educación y las colaboraciones transfronterizas, a través del uso de la tecnología. La pandemia por la Covid-19, también ofrece la oportunidad de reiniciar y remodelar la movilidad académica, haciéndola más inclusiva y más sostenible.

Este nuevo escenario, también afectó directamente el aporte y la apropiación de las Universidades frente a la Agenda 2030, lo cual, impulsó a muchas Asociaciones, entre esas AUALCPI, a rediseñar sus actividades y trasladarlas al escenario virtual.

La Asociación de Universidades de América Latina y el Caribe para la Integración AUALCPI, que también hizo parte de esta Conferencia de Virtual Educa, con María Clara Nieto Rujana, Secretaria General Ejecutiva, viene trabajando, desde el 2016, en pro de una apropiación en las Universidades de la agenda 2030. Desde entonces, a través de diferentes escenarios académicos, como la Cátedra de Integración Latinoamericana y Caribeña, ha venido analizando el tema.

Para este año, dada la coyuntura de la pandemia, el evento que tradicionalmente ha sido presencial, fue aplazado; sin embargo, a partir de agosto de 2020, se realizarán pre-sesiones académicas virtuales, donde se analizará el impacto de los ODS en la educación superior, en tiempos de pandemia.

Teniendo en cuenta que la movilidad es un factor determinante para la internacionalización de las IES, se presentó a los miembros de AUALCPI el Plan de Internacionalización de la Educación a Distancia (PIED), que pretende fortalecer la cooperación regional, desde ofertas conjuntas virtuales.

Nos estamos enfrentando a un escenario nunca antes vivido en la Educación Superior, que nos motiva a pensar que un mundo conectado puede sortear, de mejor manera, la crisis. Muchos hablan de una "nueva normalidad", en la que se deberá pensar en cambios estructurales y disruptivos, para garantizar la continuidad. La Universidad del 2030, tal y como la habíamos concebido algunos años, se deberá replantear.

Sin lugar a dudas, las Universidades tendrán, en algún momento, que reabrir sus puertas, con todos los quebrantamientos que contrajeron por la pandemia: recesión económica y deserción de estudiantes. Frente a este contexto, el apoyo del Estado será fundamental, para garantizar, por un lado, el derecho a la educación superior y, por otro, una educación con calidad, en línea con los propósitos planteados en los Objetivos de Desarrollo Sostenible de Naciones Unidas.

Estos son desafíos inminentes, pero también hablemos de un contingente cambio que se hace necesario. Hasta hoy, la educación no había aprovechado el potencial transformador de la tecnología y esto ocurre, en parte, por falta de acceso equitativo a plataformas y dispositivos. Igualmente, determinantes son la baja adopción de 
herramientas digitales por las Universidades y por los docentes y los bajos niveles de conectividad en los hogares vulnerables, que impiden el acceso a la educación remota, a través del uso de las Tecnologías de la Información y la Comunicación (TIC), ampliando el rezago en la calidad de la educación en esta población (OECD, 2020); sin embargo, el impacto final o global del coronavirus Sars-Cov2, mejor conocido como COVID-19, es una pregunta sin respuesta, ya que todavía es mucho lo que puede golpear la pandemia por un tiempo, todavía indeterminado.

La situación actual no tiene precedentes, de modo que, hay un buen número de incertidumbres en torno a las proyecciones planteadas por todas las Naciones del mundo, con escenarios supuestos, para mitigar los infortunios sociales y económicos.

\section{REFERENCIAS}

1. CENTRO DE LOS OBJETIVOS DE DESARROLLO SOSTENIBLE PARA AMÉRICA LATINA - CODS. 2020. Índice ODS 2019 para América Latina y el Caribe. 135p. Disponible desde Internet en: https:/ / cods.uniandes. edu.co/wp-content/uploads/2020/06/\%C3\%8DndiceODS-2019-para-Am\%C3\%A9rica-Latina-y-el-Caribe-2. pdf (con acceso 27/07/2020).

2. INSTITUTO INTERNACIONAL DE LA UNESCO PARA LA EDUCACIÓN SUPERIOR EN AMÉRICA LATINA Y EL CARIBE - IESALC. 2020. Informe del IESALC analiza los impactos del \#covid19 y ofrece recomendaciones a gobiernos e instituciones de educación superior. Disponible desde Internet en: https://www. iesalc.unesco.org/2020/04/14/iesalc-insta-a-los-estados- a-asegurar-el-derecho-a-la-educacion-superior-enigualdad-de-oportunidades-ante-el-covid-19/ (con acceso $27 / 07 / 2020)$.

3. NACIONES UNIDAS. 2020. Shared responsibility, Global solidarity: Responding to the socio-economic impacts of COVID-19. Available from: https://unsdg.un.org/sites/ default/files/2020-03/SG-Report-Socio-EconomicImpact-of-Covid19.pdf (con acceso 27/07/2020).

4. ORGANIZACIÓN PARA LA COOPERACIÓN Y EL DESARROLLO ECONÓMICOS - OECD. 2020. La economía mundial en la cuerda floja. Perspectivas Económicas de la OCDE, junio de 2020. Disponible desde Internet en: http://www.oecd.org/perspectivaseconomicas/junio-2020/ (con acceso 27/07/2020).

5. ORGANIZACIÓN INTERNACIONAL DEL TRABAJO - OIT. 2020. Observatorio de la OIT: La COVID-19 y el mundo del trabajo. Estimaciones actualizadas y análisis. Quinta edición. Disponible desde Internet en: https:// www.ilo.org/wcmsp5/groups/public/@dgreports/@ dcomm/documents/briefingnote/wcms_749470.pdf (con acceso $27 / 07 / 2020$ ).

6. UNITED NATIONS SUSTAINABLE DEVELOPMENT GROUP - UNSDG. 2020. Shared responsability, global solidarity: Responding to socio-economic impacts of Covid-19. Disponible desde Internet en: https:// unsdg.un.org/sites/default/files/2020-03/SG-ReportSocio-Economic-Impact-of-Covid19.pdf (con acceso 27/07/2020). 